\title{
Article \\ Leading in Switzerland and Poland: A Case Study of Leadership Practices in Financial Services
}

\author{
Marc Steinmann and Carlo Pugnetti *
}

check for

updates

Citation: Steinmann, Marc, and Carlo Pugnetti. 2021. Leading in Switzerland and Poland: A Case Study of Leadership Practices in Financial Services. International Journal of Financial Studies 9: 6. https://doi.org/10.3390/ijfs9010006

Received: 13 November 2020 Accepted: 31 December 2020 Published: 6 January 2021

Publisher's Note: MDPI stays neutral with regard to jurisdictional clai$\mathrm{ms}$ in published maps and institutional affiliations.

Copyright: (C) 2021 by the authors. Licensee MDPI, Basel, Switzerland. This article is an open access article distributed under the terms and conditions of the Creative Commons Attribution (CC BY) license (https:// creativecommons.org/licenses/by/ $4.0 /)$.
School of Management and Law, Zurich University of Applied Sciences, 8401 Winterthur, Switzerland; marc.steinmann@gmx.ch

* Correspondence: carlo.pugnetti@zhaw.ch; Tel.: +41-79-470-6375
Abstract: Leading across national borders is a challenge, partly due to the cultural differences among employees in different locations. We investigate this dynamic for employees of a Swiss financial services company located in Switzerland and in Poland by surveying employees about their leadership expectations and experiences, as well as about their cultural values. We find that the leadership expectations of employees in these two locations do not differ significantly. However, their experience does, indicating the opportunity for further development of local Polish management practices and leadership behavior, and underlying the importance of local leadership development. In addition, we find that a few cultural dimensions have a significant impact on leadership expectations in both countries, indicating the opportunity to further refine situational leadership behavior throughout the organization independently of location. While organizations spanning across Western and Central European locations need to deal with significant differences in cultural and leadership expectation, our results suggest that they can effectively align leadership practices and thus mitigate the practical challenges arising from these differences.

Keywords: leadership; near-shoring; culture

JEL Classification: F23; M14; M16

\section{Introduction}

As companies increasingly develop more efficient cross-border business models and the international organizational structures to support them, they face the challenge of how to manage these culturally diverse and geographically distributed organizations (Focarelli and Pozzolo 2001; Duan et al. 2020). Joshi and Lazarova (2005) studied leadership competencies in multinational teams and highlighted that it is more challenging to share resources, transfer know-how and collaborate in a global setting because of national or cultural differences as well as physical distance. Organizational structure, system integration and process design are important components of solving this challenge. Most importantly however, individuals in the organization need to interact effectively with each other. Leading across borders and cultures thus presents an additional set of significant and important challenges.

This study focuses on the assessment of interpersonal leadership in a Swiss financial services company from the perspective of staff located in Switzerland and Poland, mainly operating in classic back-office or project management functions. Critical for inclusion in the study is that organizational units share responsibility for a portfolio of tasks or a project across the two locations, and are managed by a team leader based in one of the locations. While the company operates globally, this research concentrates on employees based in Poland and Switzerland as these are the main locations for back office activities. Several Polish employees have worked in Switzerland as part of their career development and a growing number of non-Polish nationals have been hired in Poland as near-shoring has grown. About $85 \%$ of the employees located in Poland are Polish nationals; the rest 
represent a mix of more than 50 different nationalities. In Switzerland, about $80 \%$ of the workforce consists of Swiss nationals and the other $20 \%$ are of different national origins. The company embeds a leadership framework in its management training, and this element is also integrated into all people-related leadership responsibilities to enable performance. This framework is the foundation of all managers' expected leadership behavior, and thus creates a common standard across the different company locations. The firm also relies on shared principles of corporate culture to select and retain staff. These also play an important role in the training and assessment of employees, thereby ensuring alignment to the company's corporate values and shared behaviors. These frameworks, however, have not been explicitly considered in the study. The name of the company is not disclosed for reasons of confidentiality

We investigated the expectations and perception of leadership and analyzed potential cultural differences as drivers of any variations with the aim to provide insights to improve the leadership practices in both locations. In particular, we asked two research questions:

1. Do employees in Switzerland and Poland have different expectations towards leadership practices and how do they experience these practices in the interactions with their manager?

2. Do cultural dimensions have an impact on how employees rate the importance of leadership practices?

The second question is important to avoid a purely country-linked label and to capture the context of specific work cultures.

The assessment uses elements of functional leadership theories and intercultural management as discussed in Section 2. We focused on interpersonal leadership as defined by Seelhofer (2017) as leading small teams, normally no more than five to eight direct reports, and involving frequent interaction between leader and followers to enable and motivate people to do their job. In the next section we provide an overview of the leadership literature relevant to our study, followed by a description of our methodology and results obtained. Finally, we discuss the insights generated and their broader implications.

\section{Background}

The Global Leadership and Organizational Behavior Effectiveness (GLOBE) project defines leadership as "the ability of an individual to influence, motivate, and enable others to contribute towards the effectiveness and success of the organizations of which they are members." Influence, motivation and achieving organizational success are key elements of the definition of leadership, and the definition is intentionally kept broad to recognize that leadership performance is likely to be different across cultures (House et al. 2004).

Seelhofer (2017) surveyed the literature on leadership from the early "Great Man" school of the 1800s focusing on implicit character traits of great leaders, through the trait, behavioral and situational approaches of the mid 1900s, where behaviors are matched to leadership challenges to improve effectiveness. Subsequent functional leadership theories contrast with these trait and behavioral theories in that they focus on how something gets done, what a leader's main responsibilities are, and what behavior contributes to the effectiveness and success of the organizational unit they lead. Adair (1973) argued that leaders should be both task-oriented and person-oriented. A leader's main responsibilities are achieving a task and maintaining the team as a cohesive unit, as well as managing individuals and satisfying a variety of their needs. Responding to criticism of the transactional nature of functional leadership models, he enhanced the original model with two transformational elements: motivating and setting an example (Adair 1988). More recently, Lord et al. (1986) found that followers have implicit assumptions and expectations in terms of the personal traits, leadership behavior and qualities their leader is supposed to demonstrate. Leadership thus is not only shaped by who a person is, what they do and in which context they operate, but also by the perception of observers who have developed their own implicit beliefs about a leader's behavior and characteristics. 
Kouzes and Posner (2007) developed the Leadership Practices Inventory (LPI) and highlight that "leadership is about relationships, about credibility, and about what you do." Leadership is an observable set of useful skills and abilities which can be strengthened and enhanced. In other words, leadership can be learned and developed. This, however, does not mean that anyone can become a leader of historical proportions. Assuming a leadership role by stepping forward when people gather can be rewarding and purposeful. Lord et al. (2020) highlighted that leadership perceptions matter for individuals progressing in their career, for team cohesion and for organizational outcomes such as performance and identification, and conclude that "context shapes not only who is seen as leaders, but also the very nature of the categories that are used to define leaders or followers."

Management and leadership have been investigated as drivers of organizational effectiveness. Some research differentiates between management, defined as focus on operational issues in getting things done with people, and leadership, which involves the influence on processes to accomplish work. However, Adair (2005) argued that management and leadership are very closely linked, and that a separation of the two is impossible. Steers et al. (2016) further supported this view and defined leadership as "the ability of a manager to influence, motivate, and enable others within the organization to contribute towards the effectiveness and success of the enterprise." Adair (2006) however also developed a critical differentiation: "you can be appointed a manager or commander, but you are not a leader until your appointment is ratified in the hearts, minds and spirits of those who work with you." Thus, leadership development starts when both the role and the required attributes to perform it widen, a comprehensive set of leadership functions is taught, and the role holders get an opportunity to practice these functions with increasing skills.

\subsection{Functional Leadership}

Kouzes and Posner (2007) established "The Five Practices of Exemplary Leadership" through extensive empirical research: model the way, inspire a shared vision, challenge the process, enable others to act, encourage the heart. They argue that leaders engage in these five practices when extraordinary things are getting done. Table 1 describes the practices and highlights what they stand for in terms of leadership experience. Kouzes and Posner (2002) further embedded these practices in the Leadership Practices Inventory (LPI) by translating the five practices into behavioral statements in order to measure how frequently an individual demonstrates those behaviors. LPI thus allows a review of areas where a manager excels and where they have opportunities to improve as a leader. LPI has been shown to be sustainable, in the sense that it has been in use to assess leaders' effectiveness for over 30 years, across multiple countries and spanning different generations (Frontiera 2012).

Table 1. The Five Practices of Exemplary Leadership (Kouzes and Posner 2007).

\begin{tabular}{ll}
\hline Practice & Description \\
\hline Model the way & $\begin{array}{l}\text { Leaders must be clear about guiding principles, clarify common values in the organization and their } \\
\text { words and deeds have to be consistent. They demonstrate deep commitment to their beliefs by } \\
\text { setting the standard and by acting as role model in daily actions. This practice is also about earning } \\
\text { the right and the respect to lead through direct involvement, because people follow first the person } \\
\text { and then the plan. }\end{array}$ \\
\hline Inspire a shared vision & $\begin{array}{l}\text { Need for leaders to imagine and envision an exciting and highly attractive future for their } \\
\text { organization. They believe in their ability to make a difference. This involves enabling people to see } \\
\text { and understand the vision of how things could be. }\end{array}$ \\
\hline
\end{tabular}


Table 1. Cont.

\begin{tabular}{ll}
\hline Practice & Description \\
\hline Challenge the process & $\begin{array}{l}\text { Leaders are pioneers and willing to step out into the unknown in their search for opportunities to } \\
\text { innovate, grow and improve. Taking risks and creating a climate for experimentation are key drivers } \\
\text { for innovation and change. } \\
\text { Making mistakes and failures are inevitable for leaders and seen as constant learning opportunities. }\end{array}$ \\
\hline Enable others to act & $\begin{array}{l}\text { This practice refers to the need for leaders to actively involve the team, to strengthen their capacity } \\
\text { and to encourage collaboration and building trust. People more likely use their energy to produce } \\
\text { extraordinary results if they feel trusted by their leader and when they have more discretion, more } \\
\text { authority and more information. }\end{array}$ \\
\hline Encourage the heart & $\begin{array}{l}\text { Need for leaders to recognize individual contribution and to create a culture of celebrating values } \\
\text { and victories. } \\
\text { Building a strong sense of collective identity and community spirit can carry a group through } \\
\text { challenging times. }\end{array}$ \\
\hline
\end{tabular}

Managers and leaders work to understand the expectations of their organizational constituents and adapt their behavior accordingly. Different theoretical frameworks have been developed to model and explain the mechanisms of this adaptation, and the combined evidence suggests that managers who adapt their behavior to conform to the expectations of others can improve their effectiveness (Sosik et al. 2002). Understanding how leaders match the expectations of their behavior is an important indicator of their effectiveness.

\subsection{Intercultural Leadership}

Hofstede (2001) argued that ideas about leadership mirror the prevailing culture of a country and that asking people to describe the qualities of good leaders is another way of requesting them to explain their culture. He defines culture as "the collective programming of the mind that distinguishes the members of one group or category of people from others" and develops a set of cultural value dimensions, enabling the positioning of countries between the poles of each cultural dimension. Trompenaars and Hampden-Turner (1998) built on this work to focus on how cultural differences affect the process of doing business and managing, and argue that "culture is like gravity: you do not experience it until you jump six feet into the air." They identified seven dimensions of culture, and a selection among predefined alternatives allows the positioning of managers along a continuum in each dimension.

GLOBE (House et al. 2004) also measured scores along cultural dimensions, but in addition made the distinction between cultural values ("the way things should be") and practices ("the way things are"). The researchers measured both values along nine cultural dimensions (shown in Table 2) and found that Hofstede's values correlate with either practices or values, but not both (Seelhofer 2017). While GLOBE's distinctions provide more detailed results across the dimensions and allow a critical comparison of the two, international leaders may struggle to decide which one to rely on in practice. A significant difference between practices and values in a society may indicate particular cross-cultural challenges. Cultural practices are usually transparent and observable, but values are deeprooted and often invisible (Seelhofer 2017). GLOBE offers a foundation to further explore such cross-cultural challenges and the distinction between values and practices has to be kept in mind when working with their results. 
Table 2. Global Leadership and Organizational Behavior Effectiveness (GLOBE) cultural dimensions (House et al. 2004).

\begin{tabular}{ll}
\hline GLOBE Cultural Dimension & Definition \\
\hline Power distance & $\begin{array}{l}\text { The degree to which members of a group expect power to be stratified and concentrated at } \\
\text { higher levels of an organization. }\end{array}$ \\
\hline Uncertainty avoidance & $\begin{array}{l}\text { The extent to which a society, organizations or groups rely on norms, rules and procedures } \\
\text { to reduce the unpredictability of future events. }\end{array}$ \\
\hline Humane orientation & $\begin{array}{l}\text { The extent to which a group of people encourages and rewards individuals' fairness, } \\
\text { altruism and generosity. }\end{array}$ \\
\hline $\begin{array}{l}\text { Collectivism I } \\
\text { (institutional collectivism) }\end{array}$ & $\begin{array}{l}\text { The degree to which society and organizations encourage and reward collective distribution } \\
\text { of resources and collective action. }\end{array}$ \\
\hline $\begin{array}{l}\text { Collectivism II } \\
\text { in-group collectivism) }\end{array}$ & $\begin{array}{l}\text { The extent to which individuals express pride, loyalty and cohesiveness in their } \\
\text { organizations or families. }\end{array}$ \\
\hline Assertiveness & $\begin{array}{l}\text { The extent to which people are assertive, confrontational and aggressive in relationships } \\
\text { with others. }\end{array}$ \\
\hline Gender egalitarianism & $\begin{array}{l}\text { The degree to which gender differences are minimized by a collective while promoting } \\
\text { gender equality. }\end{array}$ \\
\hline Future orientation & $\begin{array}{l}\text { The extent to which people are engaged in future-oriented behaviors such as planning, } \\
\text { investing in the future and delaying gratification. }\end{array}$ \\
\hline Performance orientation & $\begin{array}{l}\text { The degree to which performance improvement and excellence are encouraged and } \\
\text { rewarded by a group of people. }\end{array}$ \\
\hline
\end{tabular}

The differences between Poland and Switzerland along the GLOBE cultural dimensions can be significant. Not only are cultural values particularly important to determine leadership expectations but they also act as their precursor (Dorfman et al. 2012). For two of them-In-group collectivism and Uncertainty avoidance-Poland and German-speaking Switzerland score at different end of the spectrum, and an additional two-Assertiveness and Power distance-show large differences between the two countries. What is considered outstanding leadership in the two countries is also impacted, with especially large differences in the opinions on Participative and Self-protective styles (House et al. 2004). Koopman et al. (1999) investigated early results from GLOBE and concentrated on the differences within Europe to identify two distinct regions, North/West versus South/East Europe, with significant differences in preferred leadership styles. These cultural and leadership differences between Switzerland and Poland indicate the significance of the research questions investigated in this study.

In its last phase, the GLOBE project examined the leadership behavior of CEOs as well as their top management and concluded that "leaders who behave according to expectations are effective" (Dorfman et al. 2012). This means that if the leadership style expected by those reporting to the leader is met, the leader is accepted and an effective environment for success and meeting goals is created. Dorfman et al. (2012) also noted that leaders are most effective if cultural norms are not violated. de de Luque et al. (2015) supported this conclusion and pointed out that CEOs demonstrating a leadership behavior aligned with a society's culture are more effective in guiding their top managers and in achieving better results for their company.

The data gathered in the GLOBE study have been leveraged to gain additional insights into leadership effectiveness in different cultural environments. Dickson et al. (2003) discussed an important cultural caveat and argued that individuals adhere to cultural values differently, and not all will display the cultural values of their native culture. This may also apply to organizations which have developed a strong corporate culture. Hajro and Pudelko (2010) supported the conclusion that leaders demonstrating charismatic and transformational leadership attributes are able to build effective teams as well as to transfer and to implement successfully applied team norms. Krzykała-Schaefer (2011) examined the leadership expectations and cultural assumptions of students in Poland and compared 
them with the results collected by GLOBE to confirm that Polish students perceive leaders with charismatic/value-based attributes as most effective. Our research explores how cultural elements impact the perception of leadership in a specific company operating across its locations in Switzerland and Poland.

\section{Results}

Company employees in Switzerland and Poland were surveyed on the importance of the five leadership practices shown in Table 1, and on how often they observe their manager exhibiting this practice. In addition, they were surveyed on their perception of the nine GLOBE cultural dimensions in their work environment. Employees were asked to rank each factor on a scale of 1 to 5, with 1 meaning "not at all important" or "never", and 5 meaning "most important" or "always".

The survey retains the dimensions of the LPI framework (Kouzes and Posner 2007) and of the GLOBE study (House et al. 2004) but reduces the LPI questionnaire from 30 to 15 statements for compactness. In addition, it reduces the scoring to a common 5-point scale from the original LPI 10-point scale and GLOBE 7-point scale for consistency. Employees were further queried about their location and the location of their direct day-today supervisor. The impact of employee gender and age was not investigated.

Focus of the survey were organizational units executing back-office and project tasks across the two locations in Poland and in Switzerland and managed from either location. This comprises a total population of approximately 600 employees in Poland and 1100 employees in Switzerland. The survey took place in March 2020 and returned 129 complete answers out of approximately 500 employees contacted, building a fair sample for the analysis. As shown in Table 3, 69 respondents worked in Switzerland and 60 in Poland. Of the Polish employees, 28 had managers located in Switzerland and 32 located in Poland. All Swiss employees have managers located in Switzerland.

Table 3. Number of respondents by location and manager location.

\begin{tabular}{ccc}
\hline & Employee in CH & Employee in PL \\
\hline Manager in Switzerland & 69 & 28 \\
Manager in Poland & - & 32 \\
\hline
\end{tabular}

All results were analyzed in the aggregate and by employee location. The observed leadership experience was further analyzed by manager location. Finally, we analyzed the impact of the cultural dimensions on the importance of the leadership practices and tested for statistical significance in the answers provided by high and low scorer for each cultural dimension.

\subsection{Aggregate Results}

In general, respondents were able to clearly differentiate their responses concerning both the importance and the experience they had along the five leadership practices, as shown in Table 4.

Table 4. Importance and experience for leadership practices.

\begin{tabular}{ccc}
\hline & Importance & Experience \\
\cline { 2 - 3 } & $\boldsymbol{p}<\mathbf{0 . 0 0 1}$ & $\boldsymbol{p}<\mathbf{0 . 0 1}$ \\
\hline Model the way & 4.37 & 3.78 \\
Inspire a shared vision & 3.81 & 3.37 \\
Challenge the process & 4.07 & 3.58 \\
Enable others to act & 4.29 & 3.70 \\
Encourage the heart & 4.20 & 3.54 \\
Mean & 4.15 & 3.59 \\
\hline
\end{tabular}


Managers seem to have aligned their behavior well to employee expectations, and the results show a high correlation between the importance employees assign to the leadership practices and managers modeling the corresponding behavior, as shown in Figure 1. One practice (Encourage the heart), however, shows a gap between importance and experience, suggesting more management attention should be devoted to this dimension.

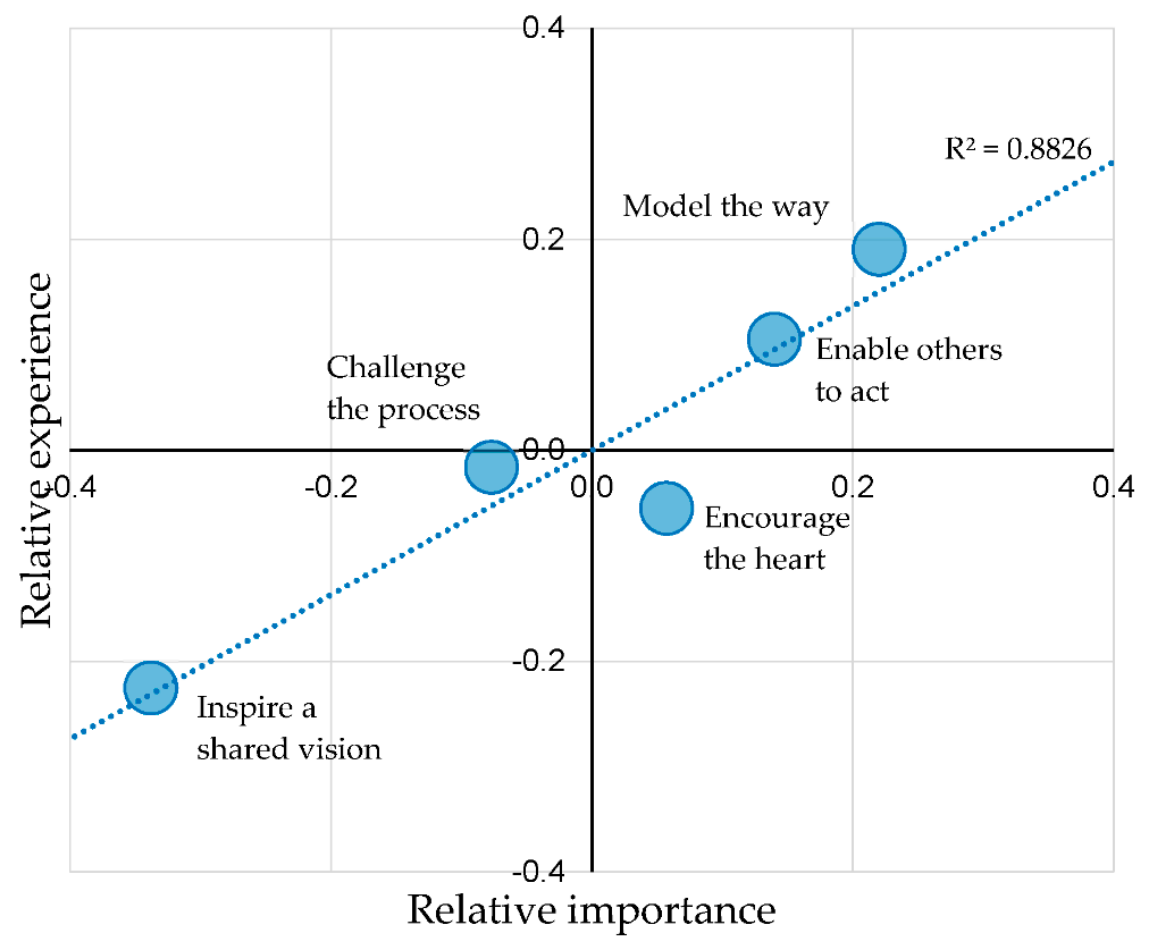

Figure 1. Relative importance vs. experience by Leadership Practice.

\subsection{Impact of Country on Leadership Practices}

Analyzing the answers provided by Swiss and Polish employees separately yields similar results, and there are no statistically significant differences in the scoring of both importance and experience between employees in the two countries, as shown in Table 5 . The difference in scoring for the importance of Model the way, however, approaches a $99 \%$ significance.

Table 5. Importance and experience for leadership practices by country.

\begin{tabular}{ccccccc}
\hline \multirow{2}{*}{ Leadership Practice } & Importance CH & PL & & Experience CH & PL \\
\cline { 2 - 6 } & $p<\mathbf{0 . 0 0 1}$ & $p<\mathbf{0 . 0 0 1}$ & & $p=0.02$ & $p=0.25$ \\
\hline Model the way & 4.49 & 4.23 & $p=0.01$ & 3.90 & 3.65 & $p=0.09$ \\
Inspire a shared vision & 3.91 & 3.69 & $p=0.11$ & 3.42 & 3.31 & $p=0.50$ \\
Challenge the process & 4.15 & 3.98 & $p=0.16$ & 3.62 & 3.53 & $p=0.57$ \\
Enable others to act & 4.32 & 4.25 & $p=0.55$ & 3.72 & 3.67 & $p=0.71$ \\
Encourage the heart & 4.12 & 4.31 & $p=0.16$ & 3.56 & 3.52 & $p=0.82$ \\
Mean & 4.20 & 4.09 & & 3.64 & 3.53 & \\
\hline
\end{tabular}

This lack of difference between Swiss and Polish employees has profound implications for leadership, indicating that the two geographies do not need different leadership approaches. The consistency may be due to a number of factors, from selection of candidates before joining the company to cultural alignment once in the company. In the first case, only certain types of candidates apply at the company, or perhaps only particular profiles succeed in navigating the interview and selection process. In the second case, new hires are 
socialized in the culture of the company or perhaps the two groups started with different profiles but have slowly co-evolved through their day-to-day interactions.

While not statistically significant, the direction of variation for Encourage the heart is different between Swiss and Polish employees, resulting in a more visible deviation from the otherwise clear correlation between importance and experience in Figure 2. This result suggests an area of further analysis into the leadership of Polish employees.
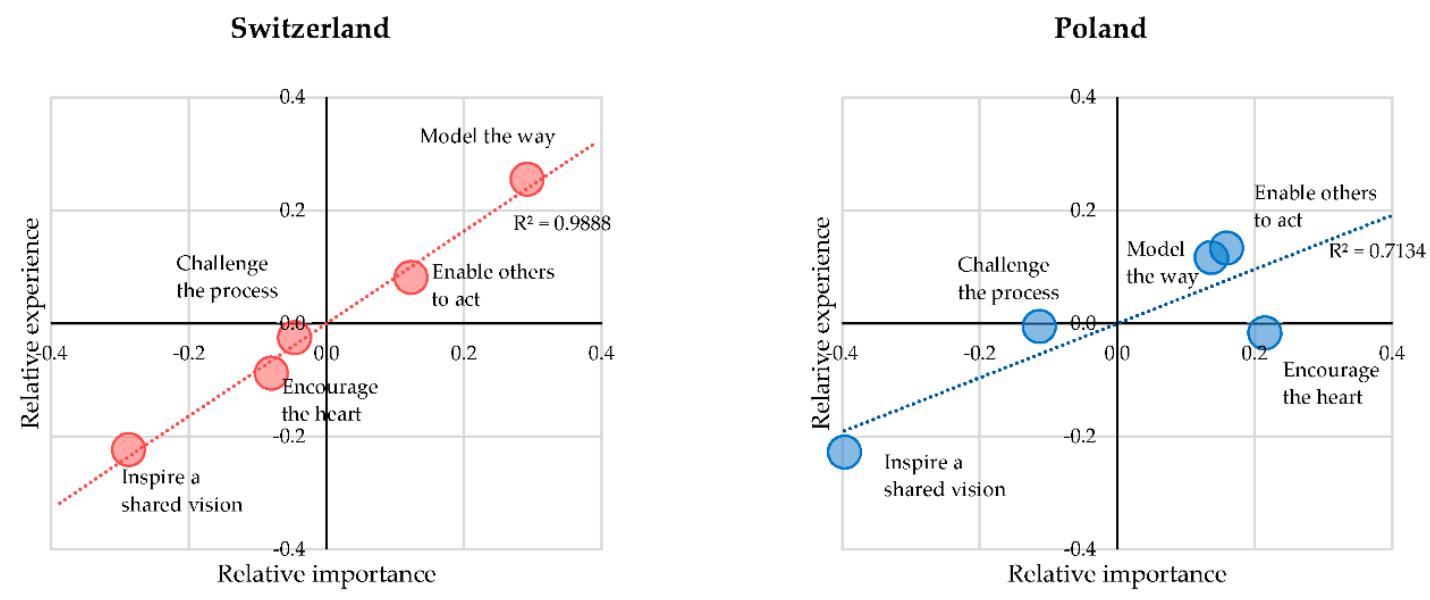

Figure 2. Relative importance vs. experience by employee country.

Polish employees, unlike Swiss employees, can have either a local manager in Poland or a manager located in Switzerland. Table 6 shows the scoring for importance and experience by Polish employees by the country of residence of their manager. Unsurprisingly, the importance of the different leadership practices is not significantly impacted by the location of the manager. The employee experience, however tends to be, with significance hovering at or just above $95 \%$. Polish employees tend to score Polish managers lower.

Table 6. Scoring of leadership practices for Polish employees by manager's country.

\begin{tabular}{ccccccc}
\hline & \multicolumn{3}{c}{ Importance } & \multicolumn{3}{c}{ Experience } \\
\hline Manager Country & CH & PL & & CH & PL \\
\hline Model the way & 4.26 & 4.20 & $p=0.70$ & 3.87 & 3.46 & $p=0.07$ \\
Inspire a shared vision & 3.73 & 3.67 & $p=0.76$ & 3.63 & 3.02 & $p=0.01$ \\
Challenge the process & 4.12 & 3.85 & $p=0.22$ & 3.83 & 3.26 & $p=0.01$ \\
Enable others to act & 4.31 & 4.20 & $p=0.56$ & 3.92 & 3.44 & $p=0.05$ \\
Encourage the heart & 4.36 & 4.26 & $p=0.63$ & 3.80 & 3.27 & $p=0.05$ \\
Mean & 4.16 & 4.04 & & 3.81 & 3.29 & \\
\hline
\end{tabular}

The relative scores, however, are consistent across Swiss and Polish leaders, with Encourage the heart representing an area of relative underperformance for both Swiss and Polish managers, as shown in Figure 3.

\subsection{Cultural Dimensions}

Employees also provided responses to score their view on the nine GLOBE cultural dimensions. There are no significant differences in the scoring between Swiss and Polish employees, with the possible exception of Power distance, as shown in Table 7. 

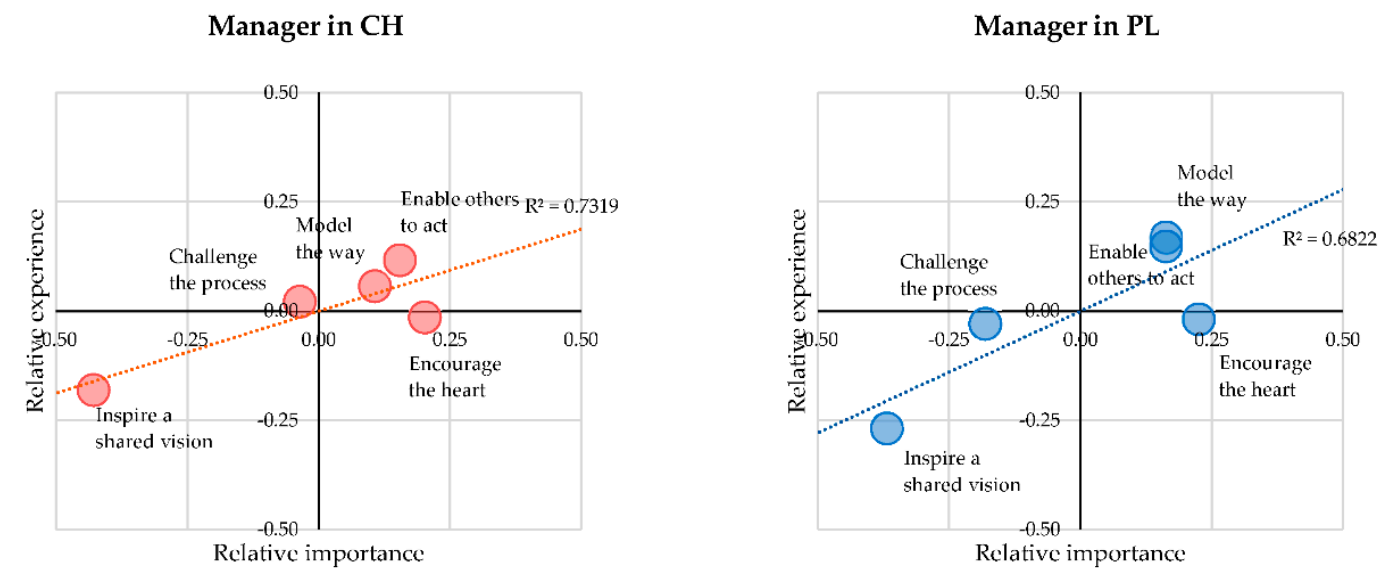

Figure 3. Relative importance vs. experience by manager country (Polish employees).

Table 7. Cultural dimensions-scores in Switzerland and Poland.

\begin{tabular}{ccccc}
\hline & Overall & CH & PL & \\
\hline Power distance & 2.51 & 2.29 & 2.77 & $p=0.02$ \\
Uncertainty avoidance & 3.03 & 3.04 & 3.02 & $p=0.87$ \\
Humane orientation & 3.32 & 3.28 & 3.36 & $p=0.58$ \\
Institutional collectivism & 2.94 & 2.91 & 2.97 & $p=0.73$ \\
In-group collectivism & 3.40 & 3.42 & 3.38 & $p=0.84$ \\
Assertiveness & 3.40 & 3.46 & 3.33 & $p=0.37$ \\
Gender egalitarianism & 4.16 & 4.19 & 4.13 & $p=0.76$ \\
Future orientation & 3.40 & 3.33 & 3.48 & $p=0.36$ \\
Performance orientation & 3.78 & 3.70 & 3.88 & $p=0.28$ \\
\hline
\end{tabular}

Further, we investigated a possible connection between individual scoring on the GLOBE cultural dimensions and the perceived importance of leadership practices. The combined results are shown in Figure 4. We used small multiples to allow a visual comparison of the results (Tufte 1990). Each graph represents scoring by Swiss and Polish employees for each leadership practice based on the score for each cultural dimension. For example, in the top left graph we can see that the scoring of Swiss employees (in orange) for the importance of Model the way hovers around 4.5 and is not influenced by a person's scoring (from 1 to 5 ) of the cultural dimension Power distance.

Overall, the relationships tend to be consistent for both Swiss and Polish employees, with a few variations especially for combinations with few data points. The scoring for Humane orientation, In-group collectivism and Future orientation, and to a smaller extent Assertiveness, seem to show a correlation with the importance of leadership practices. In Table 8 we quantify this impact by comparing the scoring of each leadership practices for high (4-5) versus low (1-2) scores for each cultural dimension. In addition, the table provides a summary of the distribution of the high versus low scores.

In-group collectivism and Future orientation, and to a lower extent Humane orientation, have a significant impact on the importance of leadership practices. Thus, while the differences between Polish and Swiss employees are small and encourage consistent leadership practices across the two locations, in-group differences along cultural dimensions are significant. This indicates that managers need to understand the make-up of their individual teams to emphasize the right leadership practice. 


\section{Power distance}

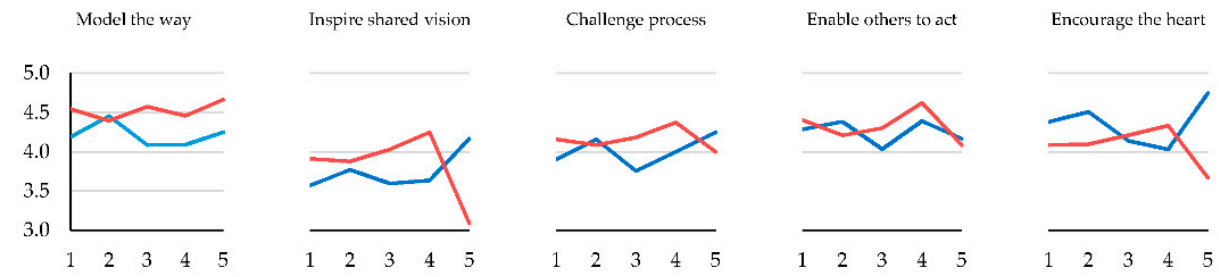

\section{Uncertainty avoidance}

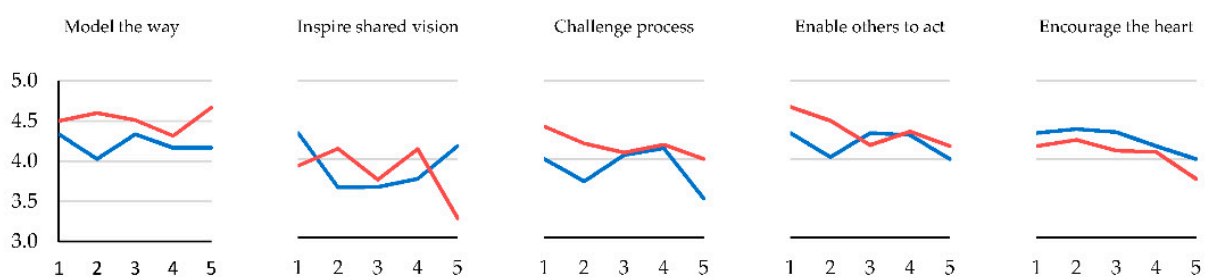

Humane orientation

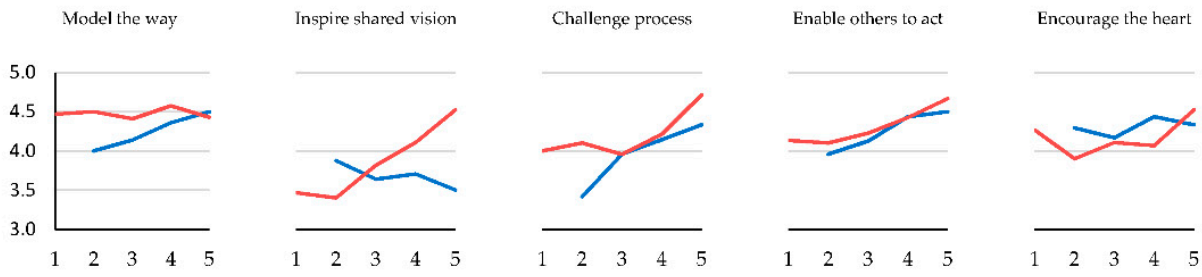

\section{Institutional collectivism}

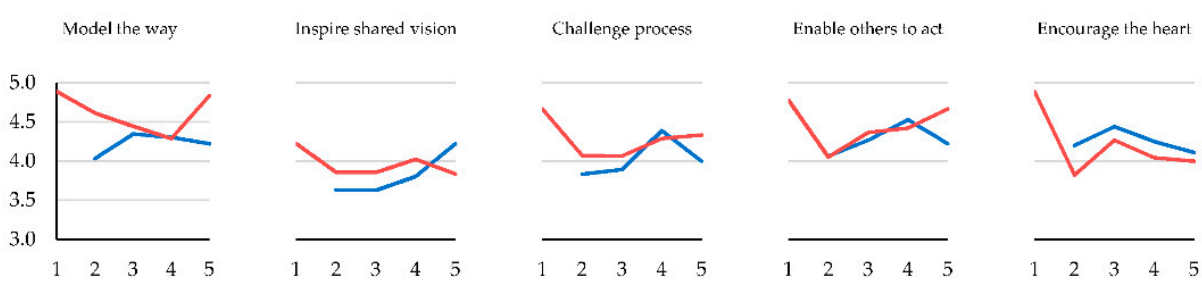

\section{In-group collectivism}

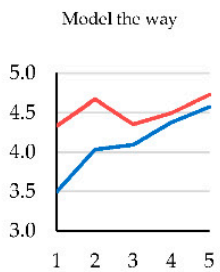

Inspire shared vision

Challenge process

Enablc others to act

Encourage the heart
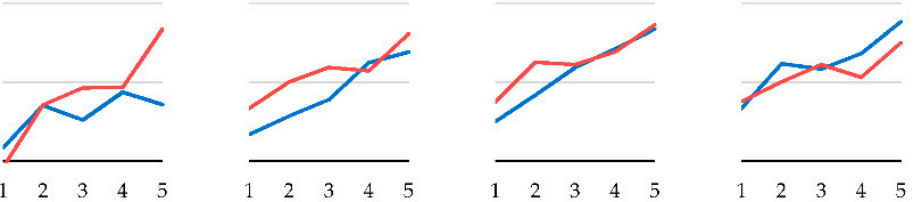

\section{Assertiveness}
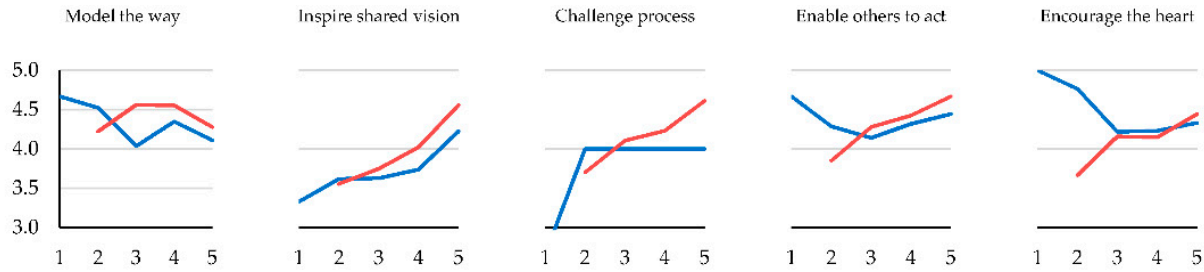

Figure 4. Cont. 
Gender egalitarianism

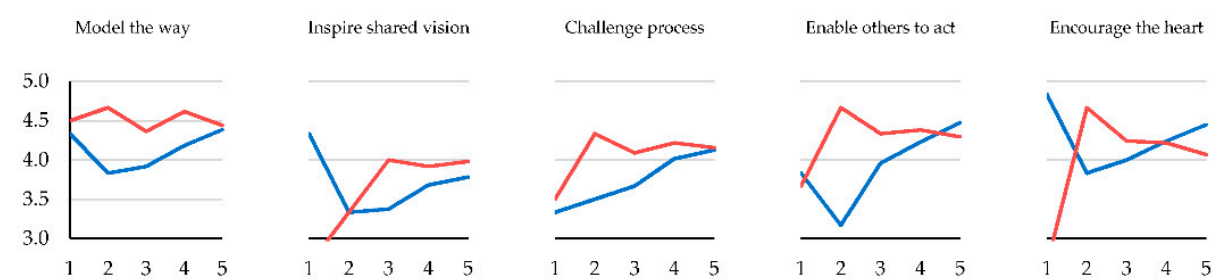

Future orientation
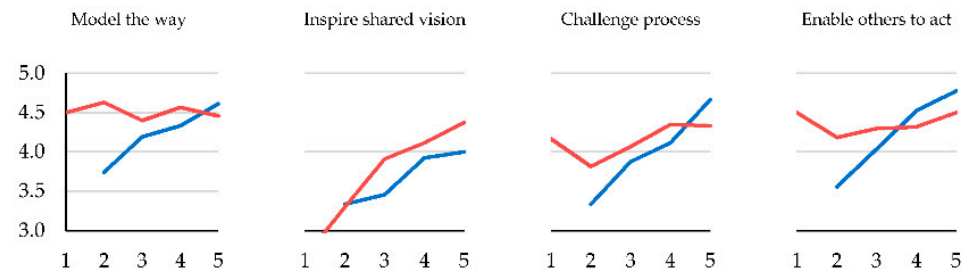

Encourage the heart

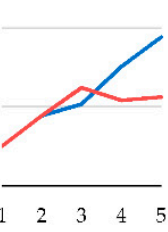

Performance orientation
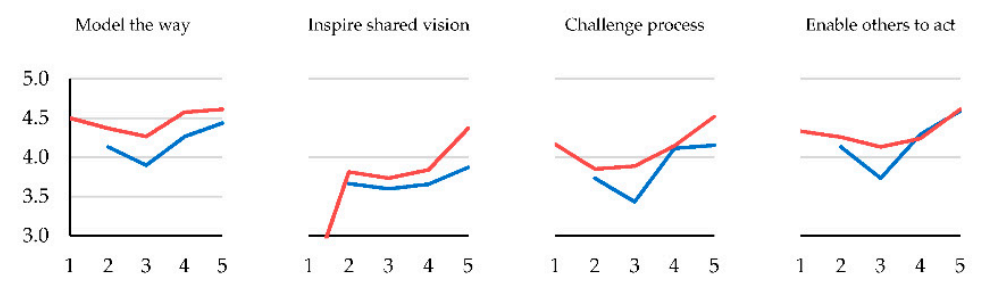

Encourage the heart

Poland $\longrightarrow$ Switzerland

Figure 4. Importance of leadership factor by score on cultural dimension.

Table 8. Impact of cultural dimensions on importance (high scores vs. low scores).

\begin{tabular}{|c|c|c|c|c|c|c|c|}
\hline & $\begin{array}{l}\text { High } \\
(4-5)\end{array}$ & $\begin{array}{r}\text { Low } \\
(1-2)\end{array}$ & $\begin{array}{c}\text { Model the } \\
\text { Way }\end{array}$ & $\begin{array}{c}\text { Inspire a } \\
\text { Shared Vision }\end{array}$ & $\begin{array}{c}\text { Challenge the } \\
\text { Process }\end{array}$ & $\begin{array}{c}\text { Enable Others } \\
\text { to Act }\end{array}$ & $\begin{array}{c}\text { Encourage the } \\
\text { Heart }\end{array}$ \\
\hline Power distance & $21 \%$ & $56 \%$ & $p=0.34$ & $p=0.94$ & $p=0.78$ & $p=0.62$ & $p=0.73$ \\
\hline Uncertainty avoidance & $28 \%$ & $26 \%$ & $p=0.72$ & $p=0.94$ & $p=0.61$ & $p=0.86$ & $p=0.22$ \\
\hline Humane orientation & $47 \%$ & $18 \%$ & $p=0.34$ & $p=0.06$ & $p=0.01$ & $p<0.01$ & $p=0.35$ \\
\hline Institutional collectivism & $25 \%$ & $33 \%$ & $p=0.81$ & $p=0.34$ & $p=0.07$ & $p=0.04$ & $p=0.82$ \\
\hline In-group collectivism & $53 \%$ & $19 \%$ & $p=0.09$ & $p=0.03$ & $p<0.001$ & $p<0.001$ & $p=0.20$ \\
\hline Assertiveness & $47 \%$ & $13 \%$ & $p=0.74$ & $p=0.05$ & $p=0.03$ & $p=0.05$ & $p=0.92$ \\
\hline Gender egalitarianism & $80 \%$ & $6 \%$ & $p=0.72$ & $p=0.12$ & $p=0.06$ & $p=0.02$ & $p=0.40$ \\
\hline Future orientation & $47 \%$ & $16 \%$ & $p=0.12$ & $p<0.001$ & $p<0.001$ & $p<0.001$ & $p<0.01$ \\
\hline Performance orientation & $68 \%$ & $12 \%$ & $p=0.38$ & $p=0.14$ & $p=0.03$ & $p=0.33$ & $p=0.08$ \\
\hline
\end{tabular}

\section{Conclusions}

The survey responses reveal interesting similarities and differences between employees in Switzerland and Poland regarding their expectations of and experiences with leadership. First, there are only minor differences in the leadership expectations of employees in both countries, and the leadership behavior seems to be aligned very well with overall employee expectations. This is a positive result, indicating a shared company culture and responsive management practices. We can only speculate as to the reasons, but a combination of strong culture in the parent company, hiring and selection processes, and socialization at work are likely candidates for this result. 
The positive correlation between expectations and experience holds strong for Swiss employees, but deteriorates somewhat for Polish employees. More precisely, the importance they attribute to different leadership practices does not change; however, their experience does. This is particularly the case for Polish employees led by local Polish management. The first result is not surprising and indicates a more mature management structure in the Swiss company; the second indicates an opportunity for further development of the local Polish leadership. It is not country-specific differences that drive these results - indeed Swiss managers of Polish employees score higher than for Swiss employees - but local development. Particular emphasis should therefore be placed on developing the Encourage the heart dimension, and to a much lesser extent Inspire a shared vision.

Encourage the heart indicates celebrating victories and sharing a common identity. While this may be challenging for a near-shore location detached to some extent from the activities in the head office, we suggest a consistent focus on building global functions, fostering internal mobility and nurturing talent with management experience in both locations. The coronavirus pandemic has already triggered the implementation of various innovative concepts to recognize outstanding performance and to thank employees, but the value of personally expressed appreciation remains high. Managers should continue to experiment with virtual informal gatherings in order to reduce social distance between team members, to create a sense of belonging and to foster team spirit. They could also establish inclusive identity markers such as a team motto.

The scoring on cultural dimensions seems to be consistent across Polish and Swiss employees, with the exception of a slightly larger power distance in Poland. This consistency again indicates a relatively homogenous culture at the company, and it is not aligned with the broader results of the GLOBE study for Switzerland and Poland. This indicates that a cultural alignment process has occurred in the organization. Interestingly, the results show a mix of Polish and Swiss characteristics. For example, the large difference between Institutional and In-group collectivism is more closely aligned with Poland, while the low score of Uncertainty avoidance (as a cultural value) is indicative of Switzerland. This alignment is reflected in the broad similarity of leadership expectations among employees in the two locations.

Further analysis reveals that some of the cultural dimensions have a significant impact on the responses regarding the importance of different leadership practices. That is, employees scoring differently along particular cultural dimensions may need to be led differently in order to better address their expectations. Future orientation and In-group collectivism in particular trigger differentiated expectations along several practices. The implications of this relationship for leadership are significant: the situational leadership requirements extend to a deeper understanding of individual team members and more targeted leadership behavior. This is true for both Swiss and Polish employees. Thus, within-group differences within a team seem to require more attention than between-group differences across Switzerland and Poland, which seem small by comparison.

This analysis was designed as a case study on a particular area of a specific organization. It is therefore difficult to generalize the results obtained, and further research is necessary. While the statistical analysis indicates robust results, the relatively small sample size needs to be noted. However, based on our results, we can hypothesize that the challenges posed by cultural differences across Western and Central European locations can be defused by creating closer cultural alignment within an organization and, in particular, differing leadership expectations can be mitigated by aligning leadership practices through a strong management training framework.

Author Contributions: Research design, survey design and analysis, review: M.S.; analysis, visualization, writing, C.P. All authors have read and agreed to the published version of the manuscript.

Funding: This research received no external funding.

Data Availability Statement: The data presented in this study are available on request from the corresponding author. The data are not publicly available due to privacy. 
Conflicts of Interest: The authors declare no conflict of interest.

\section{References}

Adair, John Eric. 1973. Action-Centered Leadership. New York: McGraw-Hill.

Adair, John Eric. 1988. Effective Leadership. London: Pan Books.

Adair, John Eric. 2005. How to Grow Leaders. The Seven Key Principles of Effective Leadership Development. London: Kogan Page Limited. Adair, John Eric. 2006. Effective Leadership Development. London: Chartered Institute of Personnel and Development.

de Luque, Mary Sully, Ariel M. Lelchook, and Narda R. 2015. Project GLOBE: Insights into the study of culture and leadership. Wiley Encyclopedia of Management, 1-9. [CrossRef]

Dickson, Marcus W., Deanne N. Den Hartog, and Jacqueline K. Mitchelson. 2003. Research on leadership in a cross-cultural context: Making progress, and raising new questions. Leadership Quarterly 14: 729-68. [CrossRef]

Dorfman, Peter, Mansour Javidan, Paul Hanges, Ali Dastmalchian, and Robert House. 2012. GLOBE: A twenty year journey into the intriguing world of culture and leadership. Journal of World Business 47: 504-18. [CrossRef]

Duan, Yunlong, Lei Huang, Hao Cheng, Lisheng Yang, and Tianzhou Ren. 2020. The moderating effect of cultural distance on the cross-border knowledge management and innovation quality of multinational corporations. Journal of Knowledge Management. [CrossRef]

Focarelli, Dario, and Alberto Franco Pozzolo. 2001. The pattern of cross-border bank mergers and shareholdings in OECD countries. Journal of Banking and Finance 25: 2305-37. [CrossRef]

Frontiera, Joe. 2012. On Leadership: The Leadership Challenge, 25 Years Later. Retrieved March 2020, from the Washington Post: August 8. Available online: https:/ / www.washingtonpost.com/national/on-leadership/the-leadership-challenge-25-yearslater/2012/08/08/f021862e-e15b-11e1-a25e-15067bb31849_story.html (accessed on 8 March 2020).

Hajro, Aida, and Markus Pudelko. 2010. An analysis of core-competences of successful multinational team leaders. International Journal of Cross Cultural Management 10: 175-94. [CrossRef]

Hofstede, Geert. 2001. Culture's Consequences: Comparing Values, Behaviors, Institutions, and Organizations across Nations, 2nd ed. Thousand Oaks: Sage Publications, Inc.

House, Robert J., Paul J. Hanges, Mansour Javidan, Peter W. Dorfman, and Vipin Gupta. 2004. Culture, Leadership, and Organizations: The GLOBE Study of 62 Societies. Thousand Oaks: SAGE Publications, Inc.

Joshi, Aparna, and Mila Lazarova. 2005. Do "Global" teams need "global" leaders? Identifying leadership competencies in multinational teams. Advances in International Management. Managing Multinational Teams: Global Perspectives 18: $281-302$.

Koopman, Paul L., Deanne N. Den Hartog, and Edvard Konrad. 1999. National culture and leadership profiles in Europe: Some results from the GLOBE study. European Journal of Work and Organizational Psychology 8: 503-20. [CrossRef]

Kouzes, James M., and Barry Z. Posner. 2002. The Leadership Practices Inventory: Theory and Evidence behind the Five Practices of Exemplary Leaders. May 12. Available online: https://media.wiley.com/assets/463/74/lc_jb_appendix.pdf (accessed on 8 March 2020).

Kouzes, James M., and Barry Z. Posner. 2007. The Leadership Challenge, 4th ed. San Francisco: John Wiley \& Sons, Inc.

Krzykała-Schaefer, Renata. 2011. Preferred leadership styles and attributes of future managers. Results of GLOBE student research project in Poland. Journal of Intercultural Management 3: 87-97.

Lord, Robert G., Christy L. De Vader, and George M. Alliger. 1986. A meta-analysis of the relation between personality traits and leadership perceptions: An application of validity generalization procedures. Journal of Applied Psychology 71: 402-10. [CrossRef]

Lord, Robert G., Olga Epitropaki, Roseanne J. Foti, and Tiffany Keller Hansbrough. 2020. Implicit leadership theories, implicit followership theories, and dynamic processing of leadership information. Annual Review of Organizational Psychology and Organizational Behavior 7: 49-74. [CrossRef]

Seelhofer, Daniel. 2017. Interpersonal Leadership: An Applied Guide. Kloten: OGMA Publishing GmbH.

Sosik, John J., Denise Potosky, and Dong I. Jung. 2002. Adaptive Self-Regulation: Meeting Others' Expectations of Leadership and Performance. The Journal of Social Psychology 142: 211-32. [CrossRef]

Steers, Richard M., Luciara Nardon, and Carlos J. Sanchez-Runde. 2016. Management across Cultures: Developing Global Competencies, 3rd ed. Cambridge: Cambridge University Press.

Trompenaars, Fons, and Charles Hampden-Turner. 1998. Riding the Waves of Culture: Understanding Cultural Diversity in Business, 2nd ed. London: Nicholas Brealey Publishing Limited.

Tufte, Edward R. 1990. Envisioning Information. Cheshire: Graphics Press. 